\title{
Making a Successful LRT-Based Regional Transit System: Lessons from Five New Start Cities
}

\author{
Gregory L. Thompson and Jeffrey R. Brown \\ Florida State University
}

\begin{abstract}
This paper examines five metropolitan areas where light rail transit (LRT) lines serve as regional transit backbones. The paper defines a successful LRT-based regional transit system as one with high riding habit and productivity for all combined modes in each metropolitan area, and as also having high LRT ridership and productivity. Based on these criteria, Portland emerges as a successful LRT-based regional transit system. Our analysis reveals three characteristics that explain the Portland transit system's strong performance: the network's dispersed nature, the overlay of a higherspeed, high-frequency regional LRT network atop the local bus system, and the use of transfers to provide passengers easy access to a diverse array of destinations. We examine the performance of all five metropolitan areas with respect to these characteristics using a combination of agency data and insights from interviews with key informants.
\end{abstract}

\section{Introduction}

A new era of transit development began in 1981 when San Diego, a city whose transit system contained only buses, opened its first regional light rail transit (LRT) line. Since then, 11 other U.S., previously bus-only metropolitan areas opened their own LRT lines. Several of these new LRT lines have become the backbones of 
metropolitan transit systems, carrying a large share of the metropolitan area's total transit ridership. In this paper, we examine transit performance in five such metropolitan areas, with the objective of identifying whether system design characteristics influence performance.. Using Portland as the model of a successful transit system, we identify three characteristics that are associated with Portland's success. These characteristics are the transit network's dispersed nature, the overlay of a higher-speed, high-frequency regional LRT network atop the local bus system, and the use of transfers to provide passengers easy access to a diverse array of destinations. We examine the degree to which the incidence of these characteristics is correlated with positive transit performance in the other four systems: Dallas, Sacramento, Salt Lake City, and San Diego. We find that better metropolitan transit performance is associated with a greater incidence of the three characteristics. We conclude by discussing the implications for planners in designing successful metropolitan transit networks.

\section{Literature Review}

Scholars examining the performance of LRT have typically looked at the mode as a stand-alone entity rather than as a component of an integrated transit system and/or have tended to emphasize the role of non-transit factors such as urban structure and land use policy as important contributors to ridership and performance. Scholars writing on the first subject tend to compare LRT to bus in terms of ridership, cost, and productivity and usually find LRT deficient (Kain 1998; Moore 1993). Scholars writing on the second subject tend to emphasize the role that strong CBDs and transit-oriented development (TOD) land use strategies play in leading to higher ridership or larger transit commute mode shares (Bernick and Cervero 1997; Cervero 2007; IURD et al. 2004). These two literatures tend to be quite distinct, with little connection between them. However, one characteristic they largely have in common is a tendency to ignore the role that LRT might play in the context of a regional transit system.

There is, however, a small but growing literature that emphasizes the role that rail transit, either LRT or heavy rail, can play as a trunk line (or backbone) in an integrated bus-rail regional system. Vuchic (2005) discusses the use of LRT as the backbone of a regional system that embraces a family of interconnected modes. Brown and Thompson (2009) found that successful rail metropolises use rail as the backbone of a multi-destination network that is structured to provide access to important destinations throughout the region. They insist that comparisons of bus 
versus rail performance have been clouded by a failure to consider the variety of roles these two modes actually play. They find that rail is a stronger performer in terms of ridership and productivity, both for itself and the regional transit system as a whole, because it serves as the backbone of an integrated system whereas express bus-based services tend to be isolated due to the desire to provide oneseat rides. Thompson and Matoff (2003) found similar results in their study of multi-destination versus radial transit systems in nine metropolitan areas. Bruun's work provides additional support for all these findings (2007). This paper extends this line of inquiry by seeking to understand the causes of variation in transit performance in five metropolitan areas in which LRT serves as the regional transit backbone.

\section{Data and Methodology}

We examined the performance of LRT-based regional transit systems in five U.S. metropolitan areas in $\mathbf{2 0 0 6}$ where LRT accounts for $\mathbf{3 0}$ percent or more of total metropolitan area transit ridership (measured on a passenger miles basis): Dallas, Portland, Sacramento, Salt Lake City, and San Diego. Each of these metropolitan areas is centered on a city that implemented LRT as part of a previously bus-only transit system since 1981. The five metropolitan areas have populations between two million and six million (U.S. Census Bureau 2008).

Our method involves documenting the performance of each metropolitan area's transit system in order to identify the most successful system. We then examine that system to determine which characteristics account for its success. We use the identified characteristics as transit network design criteria and evaluate how well each metropolitan area scores on these criteria. This scoring system serves as a hypothetical explanation for the variation in regional transit performance among the five metropolitan areas. We hypothesize that higher total scores on the set of design criteria will be associated with higher overall transit performance.

A metropolitan area's transit system consists of the aggregation of all fixed-route services in the metropolitan area. We measure system performance 1) by examining riding habit (passenger miles per capita) and productivity (passenger miles per revenue mile) at a metropolitan scale for all fixed-route modes and 2) by examining LRT ridership (passenger miles) and productivity (passenger miles per revenue mile). We construct metropolitan scale measures of riding habit and productivity by identifying all transit agencies in each metropolitan area that provide fixed- 
route service and aggregating the fixed-route ridership and service statistics to produce metropolitan totals. We do not consider vanpool or demand responsive services in this analysis.

Our analysis uses a combination of quantitative and qualitative data. We obtained ridership (passenger miles) and service (revenue miles) data from the National Transit Database using the Florida Department of Transportation's (FDOT) webbased data extraction tool (FDOT 2008). We obtained population data from the U.S. Census Bureau (2006). Using these data, we calculated riding habit (passenger miles per capita) and productivity (passenger miles per revenue mile) for the combination of all transit agencies providing fixed route service in each metropolitan area. We also obtained mode-specific ridership (passenger miles) and service (revenue miles) for LRT and for the total of all fixed-route bus service in each metropolitan area (FDOT 2008). We used these data to construct mode-based productivity measures (passenger miles per revenue mile) and to calculate the percent of all ridership and service provided by each mode. For Dallas and San Diego, we obtained commuter rail statistics, which we report for completeness.

We also obtained data from individual agencies about passenger activity (by mode, by station/stop, and in some cases, by time of day and direction) for some study areas. We obtained geographic information system (GIS) shapefile data that we used to construct maps of the regional transit systems in each metropolitan.

We provided context for these data by drawing on information gained in interviews with key informants in each metropolitan area. The key informants are individuals with a long-range perspective on bus and light rail transit development. These interviews provide information about the regional transit vision, the role the agency hoped that light rail and bus transit would play within this vision, the present-day operation and passenger use of the transit system, and other insights about systems planning.

\section{Transit Performance in Five LRT New Start Cities}

In evaluating the performance of each metropolitan area's LRT-based regional transit system, we considered both individual mode and total regional performance. We judged a regional transit system to be successful if it met four criteria: high metropolitan area riding habit, high metropolitan area service productivity, high LRT ridership, and high LRT productivity. Metropolitan area riding habit refers to the total number of passenger miles consumed on all fixed-route transit modes in 
the metropolitan area expressed on a per-person basis (passenger miles per capita). Metropolitan area service productivity refers to the number of passenger miles per revenue mile for all fixed-route modes in each metropolitan area. LRT ridership refers to the number of passenger miles traveled by LRT patrons. LRT service productivity refers to the number of passenger miles per revenue mile for LRT service.

Table 1 provides mode-based and metropolitan area ridership and productivity statistics. The top panel reports LRT ridership, service, and productivity information and expresses LRT ridership and service as percentages of all fixed-route service in each metropolitan area. The panel shows that $L R T$ ridership and service are highest in Portland and San Diego, followed by Dallas. Sacramento and Salt Lake City have much lower LRT ridership and provide much less bus and LRT service than the other three metropolitan areas. In each of the five metropolitan areas, LRT ridership accounts for 30 percent or more of the entire metropolitan area's transit ridership. The LRT ridership shares range from a low of 30 percent in Dallas to a high of 54 percent in Salt Lake City. LRT service accounts for a much smaller percent of the metropolitan area total than LRT contributes to ridership. LRT accounts for between 13 percent (Dallas) and 27 percent (Sacramento) of metropolitan area transit service. Thus, LRT is carrying a disproportionate share of metropolitan transit ridership, as one would hope. The far right column of the top panel reports LRT productivity. The most productive LRT service is in Salt Lake City, followed by Portland. Sacramento's LRT system has the lowest productivity.

The middle panels provide the same information about commuter rail services (where applicable) and fixed-route bus service. Particularly striking are the differences in bus route productivity in the five metropolitan areas. Portland has much higher bus productivity (10.32 passenger miles per revenue mile) than the other metropolitan areas. Dallas ranks second, and San Diego is not too far behind. Salt Lake City has the lowest bus productivity (4.34 passenger miles per vehicle mile) of the five metropolitan areas.

Figure 1 provides a capsule history of bus and LRT ridership over the two decades preceding the data shown in Table 1. Each metropolitan area is shown as a graph panel. The panels all feature the same scale (expressed as millions of passenger miles) and cover the same time period (1984-2006). Bus ridership is shown on top of LRT ridership in each graph. 
Table 1. Tranist Agency Performance in Five LRT New Start Cities (2006)

\begin{tabular}{|c|c|c|c|c|c|c|}
\hline \multirow[b]{2}{*}{$\begin{array}{c}\text { Metropolitan } \\
\text { Area }\end{array}$} & \multirow[b]{2}{*}{ Agency } & \multicolumn{2}{|c|}{ Ridership } & \multicolumn{2}{|c|}{ Service } & \multirow{2}{*}{$\begin{array}{c}\text { Productivity } \\
\text { Passenger } \\
\text { Miles per } \\
\text { Revenue Mile }\end{array}$} \\
\hline & & $\begin{array}{l}\text { Passenger } \\
\text { Miles }\end{array}$ & $\begin{array}{l}\% \text { of Metro } \\
\text { Area Fixed- } \\
\text { Route Total }\end{array}$ & $\begin{array}{l}\text { Revenue } \\
\text { Miles }\end{array}$ & $\begin{array}{l}\% \text { of Metro } \\
\text { Area Fixed- } \\
\text { Route Total }\end{array}$ & \\
\hline \multicolumn{7}{|c|}{ Light Rail Transit } \\
\hline Dallas & DART & $136,797,106$ & $30 \%$ & $5,096,186$ & $13 \%$ & 26.84 \\
\hline Portland & Tri-Met & $179,875,394$ & $39 \%$ & $6,377,513$ & $19 \%$ & 28.20 \\
\hline Sacramento & RT & $78,181,014$ & $50 \%$ & $3,888,222$ & $27 \%$ & 20.11 \\
\hline Salt Lake City & UTA & $86,039,042$ & $54 \%$ & $2,827,710$ & $14 \%$ & 30.43 \\
\hline San Diego & SDTI & $208,875,499$ & $44 \%$ & $8,180,189$ & $22 \%$ & 25.53 \\
\hline \multicolumn{7}{|l|}{ Commuter Rail } \\
\hline Dallas & TRE & $33,023,714$ & $7 \%$ & $1,087,437$ & $3 \%$ & 30.37 \\
\hline San Diego & NCTD & $42,970,414$ & $9 \%$ & $1,298,922$ & $3 \%$ & 33.08 \\
\hline \multicolumn{7}{|c|}{ Fixed-Route Bus Service } \\
\hline Dallas & $\begin{array}{l}\text { DART, The T, } \\
\text { DCTA }\end{array}$ & $283,748,664$ & $63 \%$ & $32,591,274$ & $84 \%$ & 8.71 \\
\hline Portland & CC, Tri-Met & $276,834,579$ & $61 \%$ & $26,821,806$ & $81 \%$ & 10.32 \\
\hline Sacramento & $\begin{array}{l}\text { Unitrans, RT, } \\
\text { Yolo, Roseville }\end{array}$ & $79,388,437$ & $50 \%$ & $10,758,943$ & $73 \%$ & 7.38 \\
\hline Salt Lake City & UTA & $72,567,090$ & $46 \%$ & $16,732,379$ & $86 \%$ & 4.34 \\
\hline San Diego & $\begin{array}{l}\text { CVT, MTS, } \\
\text { NCT, NCTD }\end{array}$ & $226,843,780$ & $47 \%$ & $27,846,175$ & $75 \%$ & 8.15 \\
\hline
\end{tabular}

Metropolitan Area Fixed-Route Transit (Total)

\begin{tabular}{llrrr}
\hline Dallas & All & $453,569,484$ & $38,774,897$ & 11.70 \\
Portland & All & $456,709,973$ & $33,199,319$ & 13.76 \\
Sacramento & All & $157,569,451$ & $14,647,165$ & 10.76 \\
Salt Lake City & All & $158,606,132$ & $19,560,089$ & 8.11 \\
San Diego & All & $478,689,693$ & $37,325,286$ & 12.82 \\
\hline
\end{tabular}

\begin{tabular}{lcc} 
Metropolitan Area Riding Habit & Population & Passenger Miles per capita \\
\hline Dallas & $6,003,967$ & 75.54 \\
Portland & $2,137,565$ & 213.66 \\
Sacramento & $2,067,117$ & 76.23 \\
Salt Lake City & $2,039,542$ & 77.77 \\
San Diego & $2,941,454$ & 162.74 \\
\hline
\end{tabular}

Source: FDOT (2008), U.S. Census Bureau (2008). 


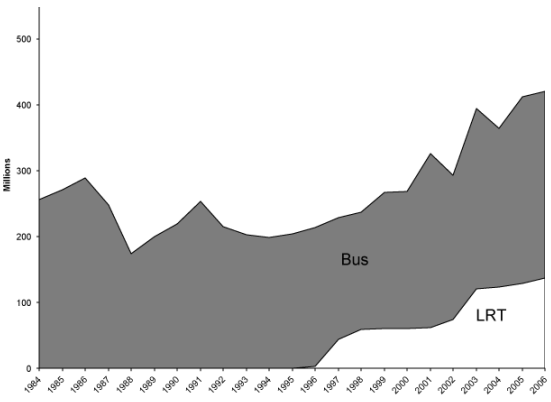

Dallas

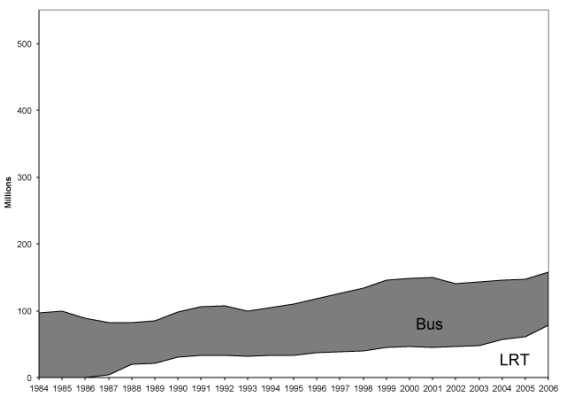

Sacramento

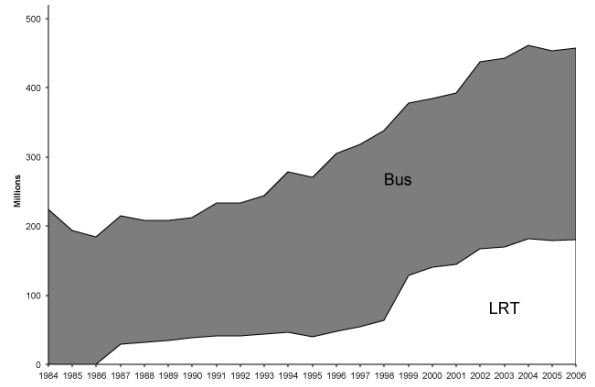

Portland

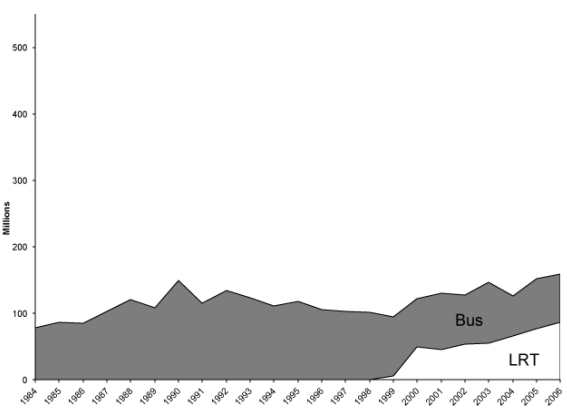

Salt Lake City

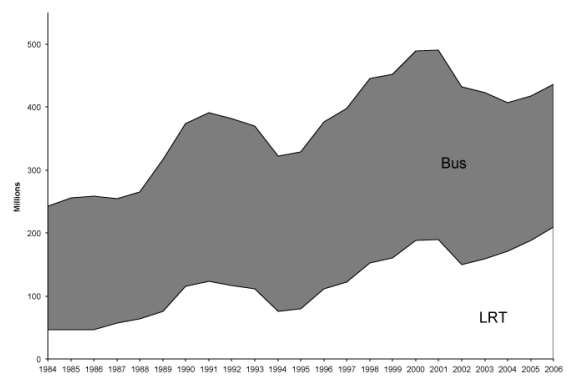

San Diego

Figure 1. Bus and LRT ridership in five metropolitan areas (1984-2006)

Two things stand out in these graphs. First, there is a sizeable difference in the magnitude of ridership among the five metropolitan areas. Ridership in Dallas, Portland, and San Diego is large and roughly comparable, although the metropolitan areas are different in terms of their total populations, leading to different riding habits, as discussed below. Ridership is much lower in Sacramento and Salt Lake City, although their populations are not very different from that of Portland. These two metropolitan areas historically have provided much less service per capita 
than the others. This fact can also be seen in the service statistics (revenue miles) for both metropolitan areas' LRT and fixed-route transit total reported in Table 1.

Second, the recent ridership increases experienced in all the cities appears to be due almost entirely to increased LRT ridership. LRT ridership has increased steadily in Dallas, Portland, Sacramento, and Salt Lake City. San Diego has also experienced a general increase in LRT ridership, although it has experienced two periods of retrenchment. Bus ridership is flat or declining in all five cities.

The other gauges of transit performance are metropolitan area service productivity and riding habit. The far right column in the fourth panel of Table 1 reports overall transit productivity for the five metropolitan areas. In 2004, fixed-route service productivity for the U.S. (excluding New York City, which alone accounts for 40 percent of all U.S. transit ridership) was 11.1 passenger miles per revenue mile (FDOT 2008). All the metropolitan areas except Sacramento and Salt Lake City had productivity above this number in 2006. Among the five metropolitan areas, Portland stands out with the highest productivity, followed by San Diego and Dallas.

The bottom table panel reports metropolitan area population and riding habit (passenger miles per capita). Riding habit adjusts ridership for population differences among the metropolitan areas. In 2004, riding habit for the U.S. (excluding New York City) was 99 passenger miles per capita (FDOT 2008). Two of the five metropolitan areas have 2006 riding habit higher than this number: Portland and San Diego. Portland stands out with significantly higher riding habit (213.66 passenger miles per capita) than second-ranked San Diego (162.74 passenger miles per capita). Dallas and Sacramento ranked at the bottom in metropolitan area riding habit and near the bottom in productivity.

Despite its high LRT productivity noted earlier, Salt Lake City falls at or near the bottom both in terms of overall riding habit and productivity. Salt Lake City's LRT line performs well by itself, but the bus service has very low productivity (4.34 passenger miles per bus mile), partly because the LRT line pulls so many riders away from the buses, as discussed later in the paper.

Based on the transit performance statistics shown in Table 1, Portland emerges as the most successful of the five metropolitan areas. It ranks first in metropolitan area riding habit and service productivity, which are the gauges of overall transit performance. Its LRT system ranks second to San Diego in ridership and second to Salt Lake City in productivity. Portland thus emerges at or near the top in the four measures we proposed to evaluate the performance of LRT-based regional transit systems. 


\section{Three Characteristics of Successful LRT-Based Regional Transit Systems}

So why is Portland so successful? Many scholars would point to the importance of land use policies in Portland that encourage more compact development and the proliferation of transit-oriented developments as fundamental to the success of the metropolitan area's transit system. While these factors undoubtedly contribute to Portland's transit ridership on the margin, the fact is that Portland's regional employment is decentralized like that in the other regions studied here. In 1970, employment in Portland's CBD stood at 30,000 jobs and represented 7.0 percent of the metropolitan area's total employment. Twenty years later, and four years after the first light rail line opened, CBD employment stood at 95,734 jobs, or 10.9 percent of the metropolitan total. From then until now, $C B D$ employment has remained flat, while total metropolitan employment has continued to grow. In 2005, CBD employment stood at 96,877 jobs, or 7.8 percent of the metropolitan total. Despite the decline in relative CBD importance between 1990 and 2005, Portland's transit system has increased its ridership and improved its productivity.

Our previous research identifies three important characteristics of Portland's transit system associated with its success (Brown and Thompson 2008). First, Portland has a dispersed transit network. A dispersed transit network is one structured to serve an array of major destinations throughout the entire metropolitan area, as opposed to one in which service is concentrated on a single major destination (usually the $\mathrm{CBD}$ ) and/or constrained to serve merely a portion of the metropolitan area. Portland's dispersed transit network predates LRT development, which has been able to tap into its existence.

Second, Portland uses LRT to provide a high-speed regional service overlay atop the local bus system. A high-speed regional overlay is higher-speed, high frequency service that lies atop the local network and works with it to allow travelers to quickly reach the wide array of major destinations throughout the metropolitan area. Portland's combined bus-rail network provides relatively quick travel between the metropolitan area's activity centers, and this makes transit more attractive to prospective riders.

Third, Portland relies on easy transfers between its bus and rail systems, as well as bus-to-bus transfers, to connect more destinations than would be possible with a system based on one-seat rides. Transfers are important evidence that passengers are taking advantage of integrated regional bus-rail transit systems to reach a wide array of regional destinations. Portland's transit system exhibits a significant amount of transfer activity. 
As a result of having these three design characteristics, Portland's transit system attracts a large number of non-CBD riders. This is important given the emergence of many other activity centers in the Portland area. Collectively, the three system design characteristics and the evidence of large non-CBD ridership are hallmarks of a regional, LRT-based multidestination transit system.

We hypothesize that variation in transit performance discussed earlier can be explained by variation in the extent to which the three design characteristics are present in each metropolitan area's transit system. We suspect that deficiencies with respect to these key characteristics as preventing the transit agencies in each metropolitan area from achieving higher ridership and productivity from their LRTbased regional transit systems.

We developed a five-point scoring system to measure the degree to which each of the three system design characteristics is present in each metropolitan area, including Portland. A score of 5 indicates that a design characteristic is fully present, while a score of 1 indicates that a characteristic is not present. Scores in between are assigned when a characteristic is largely (4), partially (3), or minimally (2) present. Table 2 provides the results of our scoring system. Portland and San Diego have the highest overall scores. Dallas and Sacramento have significantly lower overall scores. Salt Lake City has the lowest overall score. No metropolitan area receives a score of 5 on any characteristic, indicating that all metropolitan areas are deficient to one degree or another. These scores roughly correspond to the rankings of the metropolitan areas on the riding habit and service productivity measures reported at the bottom of Table 1.

\section{Table 2. Evaluation Matrix: Four Characteristics of Successful LRT Systems}

\begin{tabular}{lccccc} 
Characteristic & Portland & $\begin{array}{c}\text { San } \\
\text { Diego }\end{array}$ & Dallas & Sacramento & $\begin{array}{c}\text { Salt } \\
\text { Lake } \\
\text { City }\end{array}$ \\
\hline Dispersed transit network & 4 & 4 & 2 & 2 & 1 \\
High-speed regional service overlay & 4 & 4 & 3 & 3 & 2 \\
Utilizes transfers to reach many destinations & 4 & 4 & 2 & 2 & 1 \\
Score & $\mathbf{1 2}$ & $\mathbf{1 2}$ & $\mathbf{7}$ & $\mathbf{7}$ & $\mathbf{4}$ \\
\hline
\end{tabular}

\begin{tabular}{lll}
\hline Evaluation Scores: & 5 & Characteristic is fully present \\
& 4 & Characteristic is largely present \\
& 3 & Characteristic is partially present \\
2 & Characteristic is minimally present \\
& 1 & Characteristic is not present
\end{tabular}

In the text below, we explain how we arrived at the scoring assigned to each metropolitan area. We discuss each metropolitan area in the order presented in Table 2 , beginning with Portland. Our discussion relies heavily on insights gained from 
analyses of agency data and interviews with key informants in each metropolitan area. We also rely on Figure 2 as an important aid in our discussion of the system design characteristics. The figure provides maps of the metropolitan transit systems in each of the five metropolitan areas. The maps show local bus routes in a medium-gray color. The regional light rail transit routes are shown as a thick line atop the local bus routes on which circles (representing rail stations) are overlaid. The stops are generally spaced at one-mile intervals and often are designed to facilitate transfers between buses and trains and buses and buses as well as to provide auto access. Some stops provide planned pedestrian access to nearby destinations.

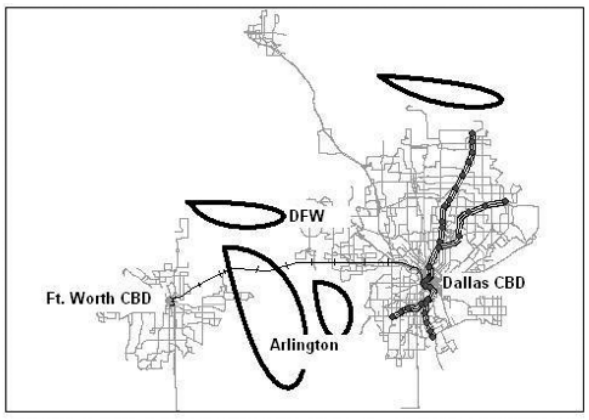

Dallas

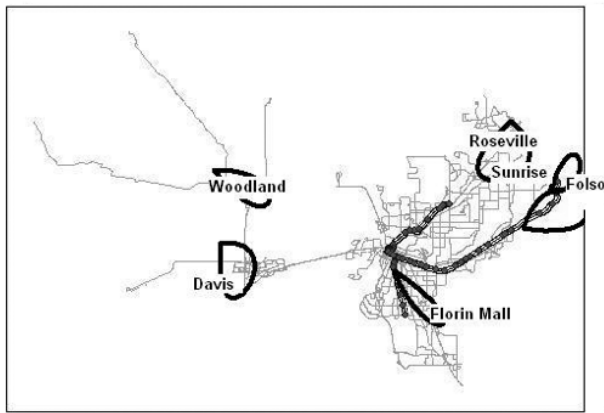

Sacramento

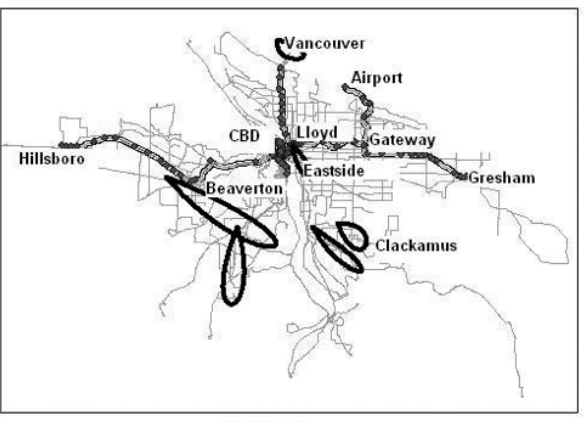

Portland

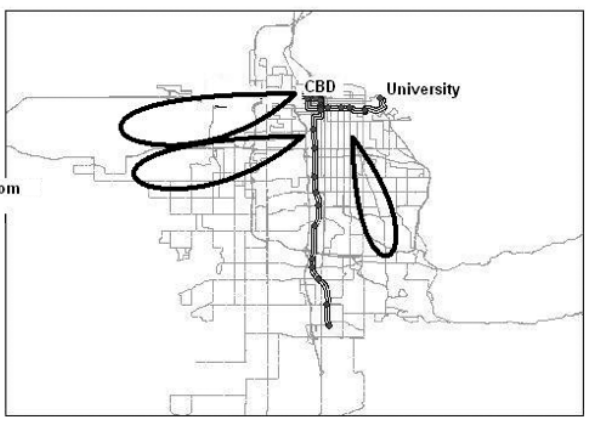

Salt Lake City

Figure 2. Regional transit system maps for five metropolitan areas

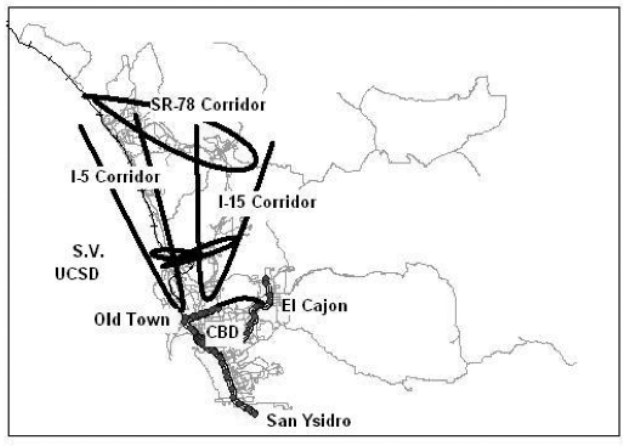

San Diego 
The regional light rail lines operate at scheduled speeds of 20 to almost 30 miles per hour compared to less than 12 miles per hour for local buses. Their headways generally are 15-minute or better. They thus represent a higher-speed, high-frequency type of service. In San Diego and Dallas, less frequent commuter rail services are shown as a narrow line with periodic cross lines. Figure 2 uses heavy black circles or arcs to indicate major regional employment centers not served by regional transit routes or not connected to them very well or at all by local bus routes.

\section{Portland}

We identified Portland as possessing a successful metropolitan transit system with all three design characteristics. But even Portland is deficient to a minor degree with respect to each characteristic, and hence we assigned it a score of 4 (characteristic is largely present) on each, for a total score of 12 .

Portland largely possesses a dispersed transit network. The map panel at the upper right in Figure 2 indicates that Portland possesses a local bus network that covers the entire metropolitan area and thus attempts to serve all the major activity centers. While nearly half Portland's bus routes serve the $C B D$, these routes serve many other destinations as well, and its most heavily patronized routes do not serve the $\mathrm{CBD}$. They operate on major arterial roads characterized by strip commercial development. Portland's bus and rail routes are integrated with each other by design, either by functioning in a grid, or through the use of timed-transfer centers. This service structure has prevailed since the late 1970s, several years before the introduction of the first LRT service in the region, but the bus restructuring was done with light rail in mind.

Portland's light rail lines function as the higher-speed regional transit overlay and are evident in Figure 2. From the time the first line opened in 1986, the regional light rail lines provided the $\mathrm{CBD}$ link for many of the previously restructured bus routes in each light rail corridor. The light rail lines operate at a scheduled speed of about twice as fast as local buses and serve not only the CBD but major and growing employment centers to both the east and west. There still are many major employment centers not served by regional transit in Portland, as indicated by the circles in Figure 2. For this reason, Portland does not get a perfect score on this characteristic. However, all these employment clusters and corridors are served by local buses that connect with regional transit service.

As noted earlier, transfers are important evidence that passengers are taking advantage of integrated regional bus-rail transit systems to reach a wide array of 
regional destinations. If transfer activity merely indicated forced shifting from one mode to another, we would expect to find high levels of transfer activity to be associated with stagnant or declining patronage transit systems. However, we find that high levels of transfer activity tend to be associated with strong and growing patronage systems.

Portland's transit system illustrates the importance of transfers for successful regional transit system performance. Figure 3 shows average weekday LRT boardings by station in spring 2007. The stations with the highest numbers of boardings are major transfer centers, including the Cedar Hills, Beaverton, and Gateway timed transfer centers, Hollywood, Northeast 82nd Avenue, and Northeast 60th Avenue.

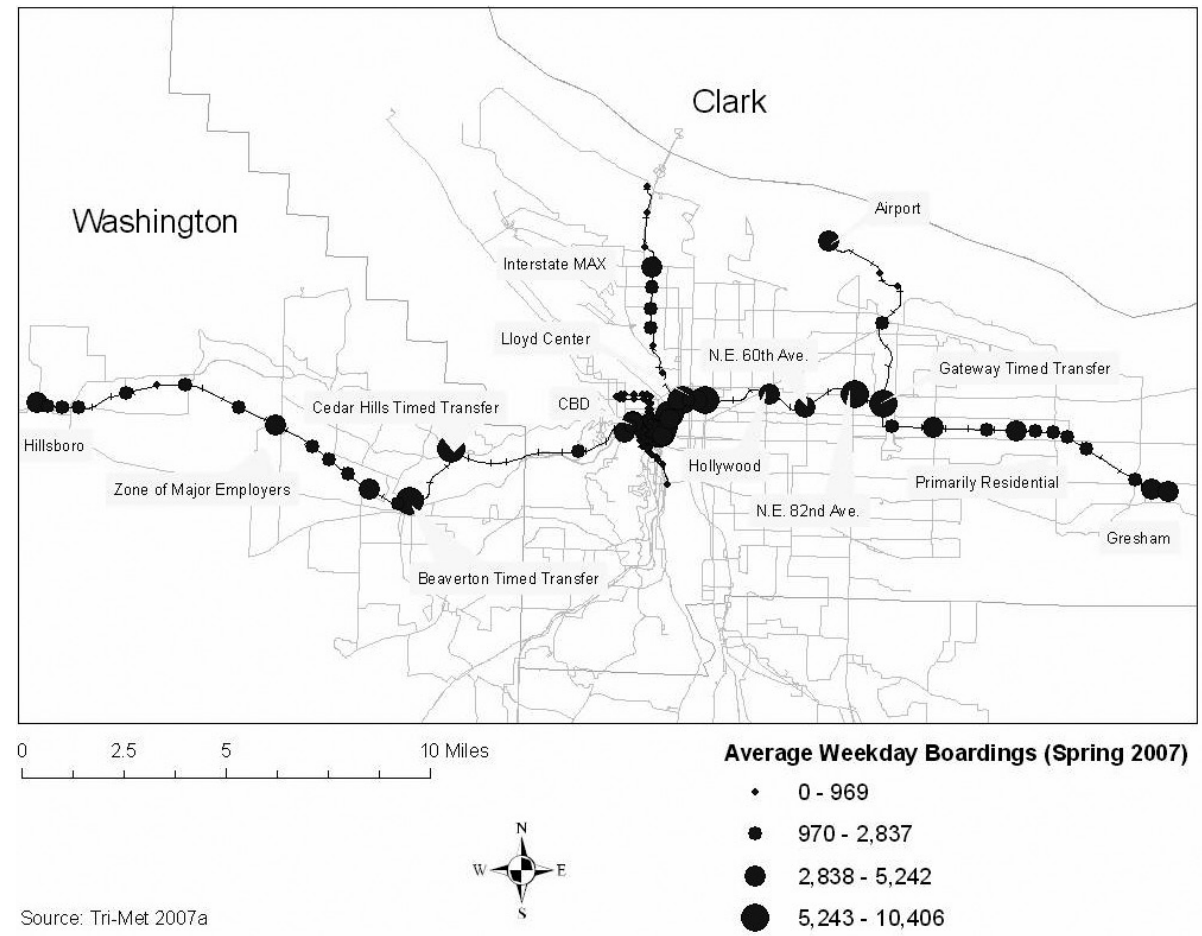

Figure 3. Average weekday boardings at Portland LRT stations (Spring 2007)

\section{San Diego}

We also identified San Diego as having a successful transit system (based on the discussion around Table 1). Like Portland, San Diego possesses all three design char- 
acteristics. Also like Portland, it is deficient to at least a minor degree on each of the characteristics, and hence we also assigned it scores of 4 for an overall score of 12 .

The bottom map panel in Figure 2 shows that San Diego's transit coverage resembles Portland's but it is even more decentralized. San Diego's local bus network blankets the entire urbanized area. Although it is operated by numerous agencies, it and the various rail services are integrated by a centralized board into a cohesive network. A large percentage of bus routes terminate at light rail stations rather than continuing to the $C B D$ as they did before the various light rail lines opened.

San Diego's LRT system functions as the region's high-speed service overlay. The light rail lines operate at much higher scheduled speeds than local buses and cover the major employment corridors in the south county. The west-east line running from Old Town to El Cajon (see Figure 2) does not serve the CBD but instead runs through the linear edge city area known as Mission Valley. As in Portland, San Diego's regional transit overlay is not perfect. Several corridors containing heavy and growing employment extend north of the Mission Valley, indicated as the I-15, I-5, S.R. 78, and Sorrento Valley (S.R.) corridors in Figure 2. The I-15 corridor is served by a complex network of express buses that extend from Escondido to the San Diego CBD. Some of these buses provide non-stop service from northern neighborhoods to the San Diego CBD. Others leave the freeway to stop at intermediate stops, including a major transfer station with the Mission Valley light rail line. The $1-5$ corridor has a similar pattern of express buses plus a commuter rail service that extends from Oceanside to the San Diego CBD, while also stopping at large employment concentrations and transfer connections at Sorrento Valley (S.R. on Figure 2), and Old Town. Service is fast but infrequent.

The service quality in these corridors is far lower than that in the light rail corridors. The bus and commuter rail services reach fewer intermediate destinations, have (in the case of bus) slower speeds to intermediate destinations, and offer much less frequent service. Whereas light rail corridors carry 25,000 to 50,000 daily passengers, the northern express bus and commuter rail corridors carry less than 6,000 daily passengers. (A regional light rail line opened in the State Route 78 corridor in March 2008, too late to affect the data in this paper.)

Like Portland, San Diego's transit system relies heavily on transfers to allow patrons to reach widely dispersed destinations. Figure 4 displays passenger activity prior to the opening of the non-CBD-serving Mission Valley LRT line. The most heavilypatronized stops are those characterized by high transfer activity, including the region's two most heavily-patronized stops (Old Town Transit Center and 12th and 
Imperial Station). Half the top 20 transit stops in the region are major transfer centers, and nearly all these stops saw passenger activity increase between 2005 and 2006 (see Table 3). Most stops listed in the table with declining patronage between 2005 and 2006 are stops in the CBD. In January 2008, San Diego abolished free transfers as part of a budget balancing strategy. This poses serious challenges to a transit system whose structure is predicated on easy passenger transfer activity below Portland. The effects of this policy change on patronage will bear watching.

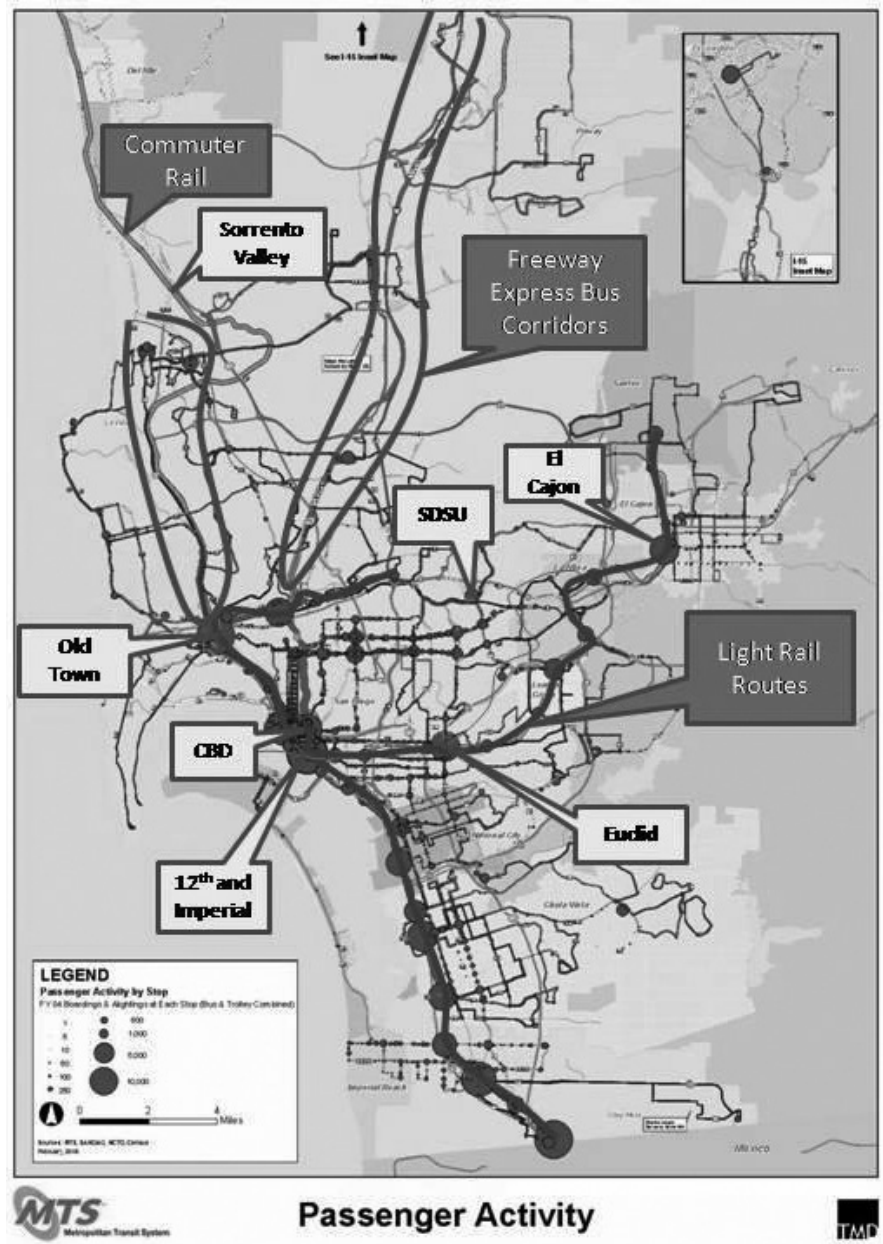

Figure 4. Passenger activity at San Diego rail stations and bus stops (2005) 


\section{Table 3. San Diego Top 20 Transit Stops in Fiscal Year 2005 and 2006}

\begin{tabular}{lccccr} 
Stop & $\begin{array}{c}\text { FY 2005 } \\
\text { Rank }\end{array}$ & $\begin{array}{c}\text { FY 2006 } \\
\text { Rank }\end{array}$ & $\begin{array}{c}\text { FY 2005 } \\
\text { Trip Ends }\end{array}$ & $\begin{array}{r}\text { FY 2006 } \\
\text { Trip Ends }\end{array}$ & $\begin{array}{r}\text { \% Change } \\
\mathbf{2 0 0 5 - 2 0 0 6}\end{array}$ \\
\hline Old Town Transit Center & 2 & 1 & 20,574 & 31,958 & $55.33 \%$ \\
12th and Imperial Station & 1 & 2 & 20,639 & 21,858 & $5.91 \%$ \\
International Border Station & 3 & 3 & 19,849 & 20,949 & $5.54 \%$ \\
Iris Avenue Trolley Station & 4 & 4 & 14,977 & 15,431 & $3.03 \%$ \\
H Street Trolley Station & 5 & 5 & 11,972 & 12,210 & $1.99 \%$ \\
5th Avenue Station - C Street & 6 & 6 & 11,034 & 11,182 & $1.34 \%$ \\
El Cajon Transit Center & 11 & 7 & 8,799 & 10,935 & $24.28 \%$ \\
Euclid Trolley Station & 7 & 8 & 10,381 & 10,622 & $2.32 \%$ \\
City College Station & 8 & 9 & 10,243 & 10,565 & $3.14 \%$ \\
Fashion Valley Trolley Station & 10 & 10 & 9,347 & 10,072 & $7.76 \%$ \\
Palomar Street Trolley Station & 9 & 11 & 9,988 & 9,483 & $-5.06 \%$ \\
Civic Center Station & 12 & 12 & 8,351 & 7,644 & $-8.47 \%$ \\
24th Street Trolley Station & 14 & 13 & 7,656 & 7,583 & $-0.95 \%$ \\
American Plaza & 13 & 14 & 7,938 & 7,170 & $-9.67 \%$ \\
Escondido Transit Center & 16 & 15 & 6,629 & 7,157 & $7.97 \%$ \\
San Diego State University & 36 & 16 & 2,281 & 6,968 & $205.48 \%$ \\
Vista Transit center & 15 & 17 & 6,747 & 6,794 & $0.70 \%$ \\
Park and Market Station & 21 & 18 & 5,618 & 6,106 & $8.69 \%$ \\
E Street Bayfront Trolley Station & 17 & 19 & 6,397 & 5,959 & $-6.85 \%$ \\
Oceanside Transit Center & 18 & 20 & 6,162 & 5,546 & $-10.00 \%$ \\
\hline Source SANDAG (2007) & & & & &
\end{tabular}

Source: SANDAG (2007)

\section{Dallas}

As noted earlier, Dallas's transit system has not experienced the high ridership and high productivity enjoyed by either Portland or San Diego. Dallas's regional transit system is more deficient with respect to each of the system design characteristics than either of the two metropolitan areas just discussed, with each of these characteristics being only either minimally or partially present.

As the map panel in Figure 2 indicates, the Dallas metropolitan area features a well-integrated, dispersed network of bus and regional light rail lines in its eastern third. In this area, a comprehensive network of local bus routes gradually has been restructured around two regional light rail lines that serve employment concentrations not only in the CBD but also to the north. The western third of the metropolitan area contains a traditional CBD-radial local and express bus system centered on the Fort Worth CBD. In the middle third of the metropolitan area, however, as well as to the north, lie major employment centers not served by any type of transit, as shown by circles in Figure 2. 
In the eastern half of the Dallas metropolitan area, LRT functions as a high-speed service overlay. A commuter rail line connects the Dallas and Fort Worth CBDs. It connects with the hub of the Fort Worth bus system and with the Dallas light rail lines on the edge of the Dallas CBD but is not effectively connected to employment concentrations in between. Its low service frequencies also serve to prevent it from functioning as a high-speed, high-frequency service backbone. Because local buses do not blanket many of the important destinations in the Dallas metropolitan area, because the regional overlay is less developed than in either Portland or San Diego, and because not even hybrid express buses serve employment corridors not served by regional transit routes, we rank Dallas behind Portland and San Diego in its performance on both the dispersed transit networks and regional transit overlay characteristics.

Also in the eastern half of the Dallas metropolitan area, transfers between buses or bus and rail are used to extend the array of destinations that patrons can access. Transfers are also used to a much lesser degree in the Fort Worth area. However, the two parts of the regions are not well connected, potential transfer activity is thus reduced, and patrons are able to reach far fewer of the metropolitan area's widely dispersed destinations.

\section{Sacramento}

Sacramento's transit system has also not experienced the high ridership and high productivity enjoyed by either Portland or San Diego. Sacramento's regional transit system is more deficient with respect to each of the system design characteristics than either of the two metropolitan areas just discussed, with each of these characteristics being only either minimally or partially present.

Sacramento is a metropolitan area that once possessed a transit system characterized by the design features seen in Portland and San Diego, but has retrogressed in recent years. Until 2000, Sacramento possessed a dispersed regional network in which bus and rail lines worked together to serve a wide array of major destinations within the metropolitan core county. But light rail extensions built since 2000 have been less well integrated into the regional transit system. The extension of a light rail line to the south was similar to San Diego's first light rail line to San Ysidro in that it ran well to the west of the previously established spine of transit service. Unlike in San Diego, however, Sacramento failed to move bus transfer centers (one of which is serving a dying mall) from the old spine to the regional light rail line (see map panel in Figure 2). Unlike the spectacular patronage growth that San Diego 
experienced on both its rail and bus services in its first light rail corridor, Sacramento has experienced only lackluster success for its south corridor.

Figure 2 also shows that the more recent extension of light rail to Folsom is similar to the Dallas commuter rail line running near areas of high employment without connections to the employment. Finally, employment clusters in Davis, Woodland, and Roseville are served by express bus service that is designed to take residents of those places to the Sacramento CBD but not to take residents from the rest of the region to employment in those centers. It should do both. Thus, there now exists in the Sacramento area significant destination concentrations that are unconnected to the transit network. We conclude that the Sacramento metropolitan area has only pieces of both a dispersed transit network and a high-speed regional overlay.

We see evidence of the importance of transfer activity in the part of the Sacramento areas where local bus services are integrated with regional rail services. In Sacramento the most heavily patronized LRT station is the 16th Street Transfer Station where patrons transfer between two LRT lines. Unfortunately, the lack of a truly dispersed regional network has served to reduce the amount of transfer activity that might otherwise take place if riders could reach the presently unserved major destinations.

\section{Salt Lake City}

Earlier, we noted that the LRT portion of the Salt Lake City transit system is performing very well, but that the transit system as a whole is not doing well due to the very poor performance of the bus system. Overall, Salt Lake City was the worst performing of the five metropolitan areas. Salt Lake City also came out ranked worse on the scoring matrix used in Table 2. It is important to note that our data depict transit in Salt Lake City before 2007 when it was organized closer to the radial archetype than the other four metropolitan areas in this paper. Beginning with a local bus route restructuring in 2007 and with the more recent inauguration of regional commuter rail service oriented to travel in both in-bound and out-bound directions, the transit system now appears to be decentralizing. What we describe is the period before 2007.

Then as now, the Salt Lake City metropolitan area contained three distinct sub areas: Ogden to the north, Salt Lake City in the middle, and Provo to the south. The Utah Transit Authority served the entire area, but before 2007 operated distinct CBD-focused transit systems in each of Ogden, Salt Lake City, and Provo. Freeway express buses connected Ogden and Provo to the Salt Lake CBD. 
The map panel in Figure 2 focuses only on the Salt Lake City part of the region as it was before 2007, when the transit routes functioned as a CBD-radial system characterized by little integration between its bus services or between its rail and bus services. After the 19-mile light rail system opened in three phases between 1999 and 2003, about 70 percent of the bus routes in the Salt Lake area continued to serve the CBD. For these routes, bus and rail service competed with one another in providing patrons with service to the CBD. The rail line had a much higher scheduled speed than the local bus routes, though it may have had little advantage with express buses going to the CBD. Unlike express buses, however, it served employment centers located at several stations in the southern part of its route. When the north-south LRT line opened, some CBD express buses were discontinued or truncated into outer light rail stations. Some new east-west service was added to serve light rail stations. . In general, though, these east-west services were underdeveloped, being afflicted by gaps in coverage, significant route deviations, and/or low frequency service.

In many respects the Salt Lake City system resembled Portland's east side bus network prior to its restructuring. At one time, Portland had numerous parallel east-west bus routes that provided low-frequency service to the Portland CBD from the eastern suburbs. About 1983, Portland eliminated some east-west routes, added service to others, and added high-frequency north-south bus routes. When the LRT began operation in 1986, Tri-Met plugged it into this network as another east-west line. The recently added north-south bus lines became major feeders and distributors from light rail stations. At about its midway point, the light rail line served a major transfer stations where all of the parallel east-west bus lines bunched up to provide transfers between each other and with the light rail line.

If the 1983 and 1986 restructurings had not happened, LRT would have been a competitor with the CBD-focused, poor quality parallel bus routes that already were there, and there would have been no high quality bus routes intersecting the LRT at right angles. Portland would have enjoyed much less patronage than it has since experienced on both its LRT and bus routes. This undesirable situation resembles the pre-2007 condition in Salt Lake City. As a consequence, major employment centers to the east and west of the light rail line were inaccessible to it (see Figure 2). To reach these employment centers by bus, residents from most of the region had to ride into the $C B D$, transfer, and ride out again.

We rank Salt Lake City below Dallas and Sacramento on the dispersed transit network criterion, lower as well on the extensiveness of its regional route overlay 
(given the presence of at-best hybrid express bus service on the Ogden and Provo links, as well as the poor integration of the regional light rail line with buses), and lower for the minimal attention paid to transfer facilities. These deficiencies appear to be changing now but were present at the time of the study.

\section{Comparison of Scoring Matrix with Transit Performance}

Earlier, we defined a regional transit system as being successful if it met four criteria: high metropolitan area riding habit, high metropolitan area service productivity, high LRT ridership, and high LRT productivity. We hypothesized that the relative presence of the three system design characteristics found in Portland might explain the variation in overall transit performance among the five metropolitan areas. To evaluate this hypothesis, we compared the four performance measures reported in Table 1 with the total score for each metropolitan area reported in Table 2. We relied on a combination of visual inspection and the calculation of correlation coefficients to evaluate the hypotheses.

We found strong positive relationships between a metropolitan area's score and its metropolitan area riding habit (0.89), metropolitan service productivity (0.94), and LRT ridership (0.90). These three findings serve as evidence in support of our hypothesis. The only unexpected finding was the weak negative correlation $(-0.11)$ between LRT service productivity and metropolitan area score, which is due to Salt Lake City's very high LRT service productivity. It is likely that even this high LRT productivity would be even higher were the system design characteristics we discuss in the paper more evident in the Salt Lake City metropolitan area, as we discuss in the text. Thus, on balance, we conclude that there is a relationship between these key system design characteristics and metropolitan transit performance in these five new-start LRT metropolitan areas.

\section{One Result: High Non-CBD Ridership}

An important indication that transit patrons are relying on transfers to use dispersed transit networks with high-speed regional overlays to reach dispersed destinations is the size and/or share of riders travelling to destinations outside the CBD. CBDs are in relative decline as employment centers and major transit destinations, so successful transit systems need to tap the non-CBD ridership market. Successful systems will thus have a high percentage of non-CBD-bound riders. We find evidence for this supposition among our study metropolitan areas. 
Evidence on the importance of the non-CBD market in Portland can be found in individual bus route ridership statistics, as well as the transfer activity data shown in Figure 3 earlier. The north-south bus routes intersecting the LRT at the 82nd Avenue and Hollywood stations are respectively the most and second most heavily patronized bus routes in the Portland metropolitan area, far surpassing patronage on routes that serve the $\mathrm{CBD}$. These two routes run along arterial roads and serve strip commercial development.

In San Diego, about 80 percent of all bus routes do not serve the CBD, and we can assume that most of their patrons are not headed to the CBD. This fact suggests that the very strong performance of transit in the San Diego region results to a large extent from non-CBD passengers who make use of the system. This conclusion is reinforced by noting that for the 20 percent of bus routes that do serve the CBD, most of their passengers are going to non-CBD destinations, as well (see Table 4). Two-thirds of LRT riders, $3 / 4$ of local bus riders, 85 percent of express bus riders, and 2/3 of commuter rail riders on CBD-bound service in San Diego are not traveling to the CBD.

\section{Table 4. Destinations of Weekday AM Peak Transit Riders in Sacramento and San Diego}

\section{Sacramento LRT Riders}

Downtown Sacramento LRT stations

4,813

16th Street Transfer Station

Other LRT Stations

6,590

$11.30 \%$

Total

12,856

$51.26 \%$

$100.00 \%$

San Diego LRT Riders

\begin{tabular}{lcr}
\hline Inside San Diego CBD & $33.97 \%$ \\
Outisde San Diego CBD & 6,687 & $66.03 \%$ \\
Total & 13,000 & $\mathbf{1 0 0 . 0 0 \%}$
\end{tabular}

San Diego Commuter Rail Riders

\begin{tabular}{lcc}
\hline Inside San Diego CBD & 670 & $31.65 \%$ \\
Outisde San Diego CBD & 1,447 & $68.35 \%$ \\
Total & $\mathbf{2 , 1 1 7}$ & $\mathbf{1 0 0 . 0 0 \%}$
\end{tabular}

San Diego Bus Riders Using CBD-serving Express Routes

\begin{tabular}{lcc}
\hline Inside San Diego CBD & 400 & $14.55 \%$ \\
Outisde San Diego CBD & 2,349 & $85.45 \%$ \\
Total & $\mathbf{2 , 7 4 9}$ & $\mathbf{1 0 0 . 0 0 \%}$
\end{tabular}

San Diego Bus Riders using CBD-serving Local Routes

\begin{tabular}{lcc}
\hline Inside San Diego CBD & 2,517 & $23.37 \%$ \\
Outside San Diego CBD & 8,254 & $76.63 \%$ \\
\hline Total & $\mathbf{1 0 , 7 7 1}$ & $\mathbf{1 0 0 . 0 0 \%}$ \\
\hline
\end{tabular}

Note: Sacramento data refer to 2007 and San Diego data to fiscal year 2006.

Sources: RT (2007), SANDAG (2007) 
We see this phenomenon in Sacramento and Dallas, as well, but to a lower extent. This is perhaps to be expected given their lower performance in Table 1 and lower scores in Table 2. In Sacramento, more than 60 percent of LRT patrons use it to reach non-CBD destinations (see Table 4). It is only on Sacramento's Folsom LRT extension that there is little indication of ridership destined to suburban destinations. There are only a total of 225 morning peak passenger alightings per day at the last four stations on the Folsom extension, despite their being located near major employment centers. The lack of connecting bus service likely suppresses patronage at these stations. If such bus service existed, the Folsom light rail line likely would experience heavy ridership destined to employment at its outer end, similar to ridership that Portland enjoys on the outer ends of its light rail lines. Sacramento's LRT productivity would improve as a result.

In Dallas, 45 percent of afternoon boardings on the CBD-focused LRT system are made by passengers boarding in non-CBD locations. Clearly even the two limited networks in Sacramento and Dallas are being used heavily by non-traditional (i.e. non-CBD) riders. We have no data on passenger destinations for Salt Lake City, although the hybrid nature of its system suggests that it too carries sizeable nonCBD traffic to the university on its east-west LRT line and activity centers on its north-sought LRT line.

\section{Conclusion}

This paper identified three characteristics of the transit system in Portland that appear to explain its success in terms of high riding habit and productivity, and measured the extent to which these same characteristics are also present in four other new start cities where LRT carries 30 percent or more of all metropolitan area transit riders. In general, we find an association between metropolitan area transit performance, shown in Table 1, and the presence of these characteristics, as recorded in Table 2 and discussed in the text.

This work suggests a possible method for better planning regional transit services by setting forth attributes that these services need to possess in order to attract substantial ridership and thus obtain satisfactory riding habit and productivity. Future research should apply this framework to other metropolitan areas of different sizes or whose LRT systems are of different lineage to test the whether these propositions can be generalized. 


\section{Acknowledgments}

We thank the Mineta Transportation Institute at San Jose State University for its generous financial support of this research. We thank Douglas Allen, Mick Crandall, Jim Howell, Gary Hufstedler, William Lieberman, Anthony Palmere, Michael Wiley, and Ken Zatarain for agreeing to be interviewed for the project from which this paper is drawn. Finally, we thank the transit agencies and metropolitan planning organizations in each of the metropolitan areas for providing the data used in this analysis.

\section{References}

Bernick, M., and R. Cervero. 1997. Transit Villages in the 21st Century. New York: McGraw-Hill.

Brown, J., and G. Thompson. 2008. The Influence of Service Planning Decisions on Rail Transit Success or Failure. San Jose, CA: Mineta Transportation Institute.

Bruun, E. 2007. Route and network analysis (Chapter 3). In Better Public Transit Systems: Analyzing Investments and Performance. Chicago, IL: Planner's Press.

Cervero, R. 2007. Transit-oriented development's ridership bonus: A product of selfselection and public policies. Environment and Planning A 39(9): 2068-2085.

Florida Department of Transportation (FDOT). 2008. Florida Transit Information System 2008. http://www.lctr.eng.fiu.edu/ftis/.

Institute of Urban and Regional Development, Parsons Brinckerhoff Quade and Douglas, Inc., Bay Area Economics, and Urban land Institute. 2004. Transitoriented development in the United States: Experiences, challenges, and prospects. Transit Cooperative Research Program Report 102. Washington, DC: Transportation Research Board, National Research Council.

Kain, J. F. 1988. Choosing the wrong technology: Or how to spend billions and reduce transit use. Journal of Advanced Transportation 21(3): 197-213.

Metropolitan Transit System (MTS). 2007. San Diego Area Transit System Shapefiles. Provided by MTS Staff.

Moore, J. E. 1993. Ridership and cost on the Long Beach-Los Angeles Blue Line Train. Transportation Research Part A 27(2): 139-152. 
North Central Texas Council of Governments (NCTCOG). 2007. Year 2007 DallasFort Worth MSA transit system route shapefiles. Provided by NCTCOG staff.

Sacramento Regional Transit District (RT). 2007. Stop-level weekday ridership, JulySeptember 2007. Provided by James Drake of RT Staff.

Sacramento Area Council of Governments (SACOG). 2007. Sacramento Area Transit System shapefiles. Provided by SACOG staff.

San Diego Association of Governments (SANDAG). 2007. Transit passenger counting program. Figures calculated from boardings and alightings of individual routes identified as serving CBD, FY 2006 data. Downloaded from http://pcp. sandag.org/Home.aspx, Fall.

Thompson, G., and T. Matoff. 2003. Keeping up with the Joneses: Planning for transit in decentralizing regions. Journal of the American Planning Association 69(3): 296-312.

Tri-Met. 2007a. Route and station-based ridership: Weekday. Spring 2007 Quarter. Provided by Ken Zatarain of Tri-Met, September 19.

Tri-Met. 2007b. Transit system shapefiles for Tri-Met. Provided by Tri-Met staff (cited as Tri-Met).

Vuchic, V. 2005. Urban Transit: Operations, Planning, and Economics. Hoboken, NJ, John Wiley and Sons.

U.S. Census Bureau. 2008. Population by metropolitan area: 2006. Constructed from 2001-2006 Population estimates data by county, www.census.gov (accessed May 29).

Utah Transit Authority. 2007. Transit route shapefiles. Provided by UTA Staff.

\section{About the Authors}

Gregory L.THOMpson (glthompson@fsu.edu) is a Professor in the Department of Urban and Regional Planning at Florida State University.

JefFReY R. BRown (jrbrown3@fsu.edu) is an Assistant Professor in the Department of Urban and Regional Planning at Florida State University. 